\title{
Temperature perception on the hand during static versus dynamic contact with a surface
}

\author{
BARRY G. GREEN \\ Yale University School of Medicine, New Haven, Connecticut
}

\begin{abstract}
Innocuous cooling or heating of the forearm can evoke nociceptive sensations, such as burning, stinging, and pricking (low-threshold thermal nociception, LTN), that are inhibited by dynamic contact. In the present study, I investigated whether LTN can also be perceived on the hand, and if so, whether it is normally suppressed by active touching. Innocuous cold $\left(28^{\circ}, 25^{\circ}\right.$, and $\left.18^{\circ} \mathrm{C}\right)$ and warm $\left(38^{\circ}, 40^{\circ}\right.$, and $\left.43^{\circ} \mathrm{C}\right)$ temperatures were delivered to the distal metacarpal pads and intermediate and distal phalanges of the fingers via a handgrip thermode that subjects either statically held or actively grasped. The same temperatures were delivered to the forearm via another thermode that either rested on the arm or was touched to the arm. Subjects rated the intensity of thermal (warmth, cold) and nociceptive (e.g., burning) sensations and indicated the qualities of sensation experienced. The results showed that LTN can be perceived on the hand, although less frequently and less intensely than on the forearm. Dynamic contact inhibited nociceptive and thermal sensations on the hand, although less strongly than on the forearm. These findings indicate that temperature perception on the hand is attenuated and its quality is changed when thermal stimulation is accompanied by dynamic tactile stimulation, as it is during haptic exploration.
\end{abstract}

Thermal stimulation encountered during haptic exploration of surfaces and objects is always accompanied by touch. Despite this spatiotemporal coincidence, only one thermotactile interaction has so far been reported in which touch alters temperature perception on the hand. That interaction, termed thermal referral, was originally observed as a mislocalization of thermal sensation across the fingers (Green, 1977). When subjects touched three thermodes simultaneously with three fingers but only the outer two thermodes were heated or cooled, the center (neutral) thermode was also perceived to be warm or cold. Thermal referral, which was also studied on the forearm (Green, 1979), was hypothesized to result from an integrative mechanism that enables otherwise poorly localized temperature sensations (Cain, 1973; Dimmick, 1915; Taus, Stevens, \& Marks, 1975) to be colocalized with tactile sensations. Because prior research had found negligible effects of mechanical pressure on the perception of thermal sensation (Jones, Singer, \& Twelker, 1962), it was assumed that touch modified the spatial perception of thermal sensations without altering their perceived intensity or quality.

It was recently discovered, however, that, under some conditions, both the quality and the intensity of temperature perception can be modified by mechanical contact. This discovery followed the observation that heating or cooling the skin of the forearm to mild temperatures (e.g., $28^{\circ}, 36^{\circ} \mathrm{C}$ ) causes some individuals to feel nociceptive sensations such as burning and stinging (low-threshold thermal nociception, LTN) in addition to warmth and cold (Green \& Akirav, 2007; Green \& Pope, 2003; Green,
Roman, Schoen, \& Collins, 2008; Green \& Schoen, 2005). LTN is optimally perceived when thermal stimulation occurs as a thermode rests statically against the skin. If thermal stimulation is produced instead by touching an already cooled (or heated) thermode to the skin, LTN is greatly reduced or disappears (contact suppression). Both the occurrence of nociceptive sensations at mild temperatures and their inhibition by mechanical contact coincident with the onset of thermal stimulation were unexpected findings. First, LTN occurs at temperatures that are below the thermal thresholds of recognized nociceptors (Bessou \& Perl, 1969; Price \& Dubner, 1977; Simone \& Kajander, 1996, 1997; Tillman, Treede, Meyer, \& Campbell, 1995). Second, although touch is well known to inhibit painful sensations (Bini, Cruccu, Hagbarth, Shady, \& Torebjörk, 1984; Inui, Tsuji, \& Kakigi, 2006; Longe et al., 2001; Pertovaara, 1979; Wall \& Cronly-Dillon, 1960; Yarnitsky, Kunin, Brik, \& Sprecher, 1997), no prior studies had indicated that merely making contact with a surface was sufficient to produce inhibition.

The present study had two main aims: to determine whether LTN occurs on the hand as well as on the arm and, if it does, whether it is inhibited during active touching or grasping. Answering the first question would establish whether LTN occurs in glabrous as well as hairy skin and is thus a general property of cutaneous temperature sensitivity; answering the second question would establish whether thermal perception of surfaces and objects is different during haptic touch than it is during passive heating or cooling. 


\section{METHOD}

\section{Subjects}

Forty-four adults ( 29 female and 15 male, average age $=27.7$ years $)$ were recruited on and around the Yale University campus and were paid to participate in the experiment. All gave informed consent, were in good health, and reported no past or present neurological disorders that could affect cutaneous sensitivity of the right hand or arm.

\section{Equipment and Stimuli}

Thermal stimuli were delivered via two custom-built thermode systems: A 16-channel, $4 \times 4$ thermode array composed of $0.64 \mathrm{~cm}^{2}(8 \times$ $8 \mathrm{~mm}$ ) Peltier thermoelectric modules was used to stimulate the forearm, and a 16-channel handgrip thermode equipped with Peltier modules of the same size was used to stimulate the hand. In both systems, the skin-thermode interface temperature was monitored by a 40 -ga type- $T$ thermocouple recessed into the faceplate of all 16 modules. The thermocouple provided temperature feedback to a PID control loop programmed in LabView software. All programmable stimulus parameters were visible on a LabView virtual instrument panel, which included a real-time graphical display of the surface temperatures of all 16 Peltier modules. In both thermode systems, baseline temperature, target temperature, rate of temperature change (all with resolutions of $\left.\pm 0.1^{\circ} \mathrm{C}\right)$, and dwell time at the target temperature $( \pm 0.1 \mathrm{sec})$ were individually controlled via the LabView interface.

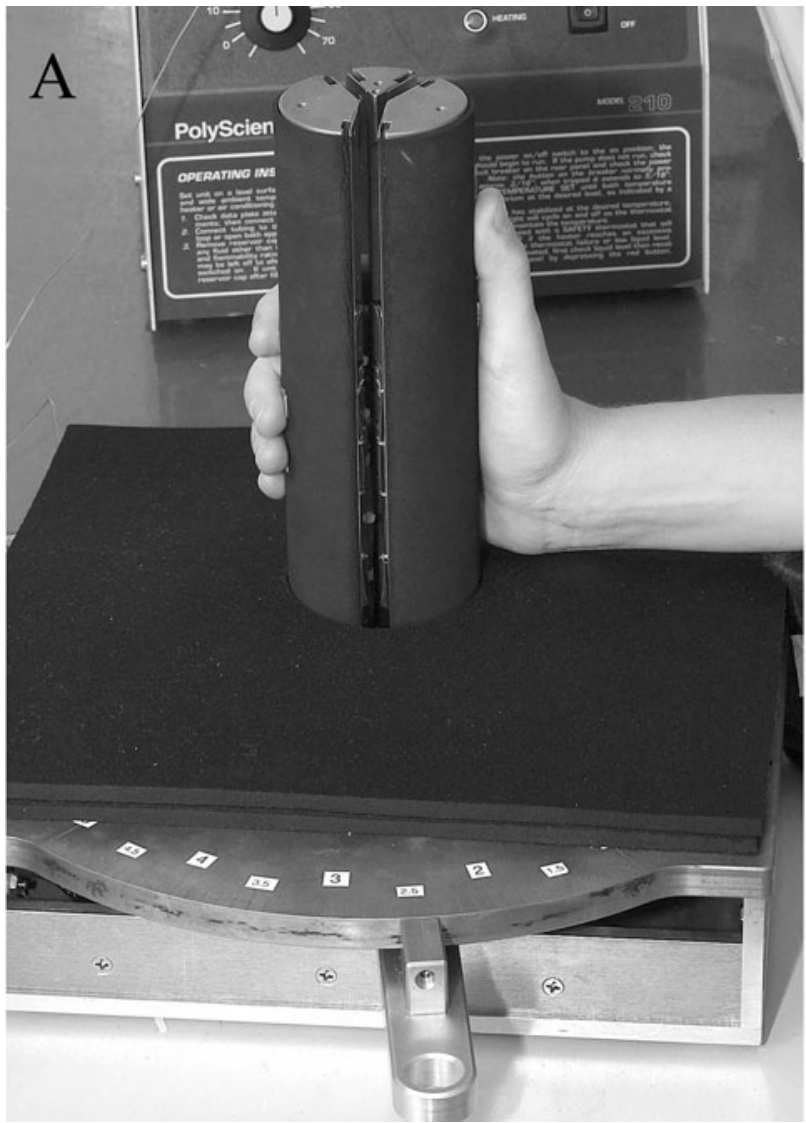

On the $4 \times 4$ thermode array, which has been used in previous studies of LTN (Green \& Schoen, 2005; Green \& Zaharchuk, 2001), the Peltier modules were spaced $2 \mathrm{~mm}$ apart and bonded with thermally conductive epoxy to a water-circulated heat sink. The thermode was fixed to a floor-mounted positioning device that stood next to a modified dental chair in which the subject sat with his or her right forearm resting on a foam pad. The thermode was positioned to make complete contact with the skin, after which the positioning arm was locked to hold the thermode in place and to prevent the full weight of the thermode from bearing on the arm.

The handgrip thermode (Figure 1) was a 12-cm-high cylinder composed of three triangular (pie-shaped) sections machined from solid copper rod that also served as water-circulated heat sinks. The 16 Peltier modules were individually bonded to the curved outside walls of the triangular sections, and the stimulating face of each module was flush with a 3/16-in.-thick neoprene material that insulated the hand from the copper heat sinks. The modules were spatially arranged on the surface of the cylinder to contact the fingers, thumb, and palm of the hand when the thermode was grasped in a natural way (e.g., as one would hold a joystick) with the thumb in a vertical orientation. Different hand sizes were accommodated manually by moving a lever at the base of the device that changed the diameter of the cylinder (from 5 to $8 \mathrm{~cm}$ ) via radial movement of its three sections. The base of the device was also covered with neoprene to cushion and thermally insulate the side of the hand

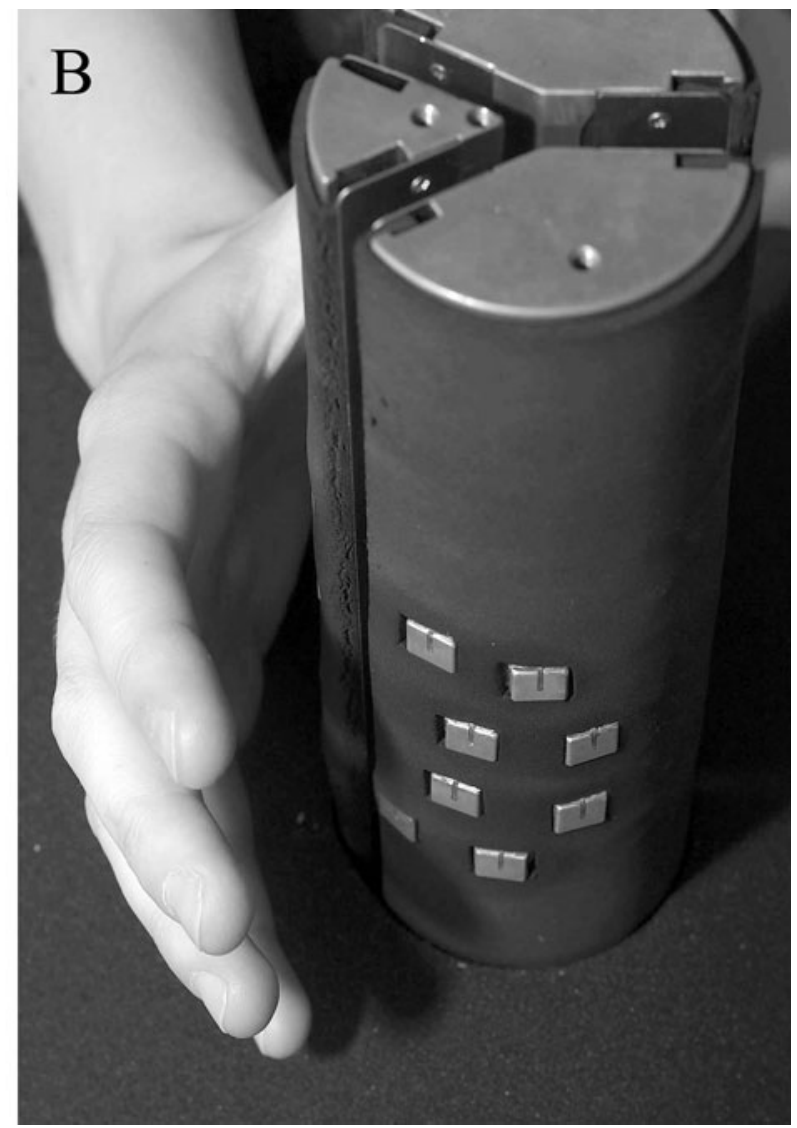

Figure 1. The 16-channel handgrip thermode. (A) Side view showing the manner in which subjects grasped the thermode during stimulation. The lever (foreground) changed the circumference of the thermode to fit hands of different size via radial movement of its three pie-shaped sections. The three sections also served as water-circulated heat sinks. (B) View showing the hand lifted from the thermode to reveal the positions of the eight Peltier modules that contacted the medial and distal phalanges of the four fingers. Four other modules (not visible) mounted on the smallest pie-shaped section of the thermode contacted the metacarpophalangeal pad at the base of each finger. The groove visible in the copper faceplate of each module contained the thermocouple wire that provided temperature feedback to the thermal control system. Black neoprene insulated the hand and arm from the metal surfaces of the heat-sinks and enabled the Peltier modules to lie flush with the surface of the handgrip. 
and wrist, and the subject's forearm and elbow were supported by a cloth-covered foam pad.

Thermal testing with both devices was conducted in a laminarflow environmental chamber with air temperature and relative humidity controlled at $26^{\circ} \mathrm{C}$ and approximately $30 \%$, respectively.

\section{Procedure}

\section{Practice Procedure}

Separate practice sessions were conducted for subjects who had not previously participated in thermal psychophysical experiments in this laboratory. The session consisted of two brief (10- to 15-min) exercises designed to give new subjects experience rating the intensity of temperature sensations using a computerized version of the general Labeled Magnitude Scale (gLMS) (Bartoshuk et al., 2003; Green, Shaffer, \& Gilmore, 1993). The gLMS is labeled at the bottom by no sensation and at the top by strongest imaginable sensation of any kind, with five other intensity descriptors (barely detectable, weak, moderate, strong, and very strong) located at empirically determined positions between the endpoints. The scale was displayed vertically on a computer screen, and, on each trial, subjects used a mouse to move a cursor to the location on the scale that corresponded to the intensity of sensation that they experienced. They then doubleclicked the mouse to save the numerical value associated with that location to a data file. In the first rating exercise, subjects were asked to imagine 16 commonly experienced temperature sensations (e.g., washing hands in cold tap water, walking barefoot on hot pavement) and to rate the remembered/imagined intensities of the sensations on the scale. This task was designed to reinforce the instructions to use the scale in the context of all possible sensations, not just those presented in the experiment. In the second exercise, subjects rated the intensity of 11 actual thermal stimuli presented to the forearm. From a base temperature of $33^{\circ}$, two series of warming $\left(38^{\circ}, 36^{\circ}\right.$, $\left.40^{\circ}, 42^{\circ} \mathrm{C}\right)$ and cooling $\left(22^{\circ}, 30^{\circ}, 28^{\circ}, 20^{\circ}, 24^{\circ}, 26^{\circ}, 18^{\circ} \mathrm{C}\right)$ stimuli were presented alternately to half ( 8 ) of the 16 modules with a 30 -sec intertrial interval (ITI). On each trial, subjects made intensity ratings of thermal sensations (cool-cold, warm-hot) and nociceptive sensations (burning, stinging, and/or pricking) on separate gLMS scales that were presented sequentially on the computer monitor. After the second intensity rating, a third screen appeared that contained a list of sensation qualities (nothing, cool, cold, warm, hot, burning, stinging/ pricking, and painful). Subjects clicked as many of the words as necessary to indicate the specific sensations that they had perceived.

\section{Experimental Procedure}

Subjects served in two experimental sessions, one for hand stimulation and one for forearm stimulation, with warm $\left(38^{\circ}, 40^{\circ}\right.$, and $\left.43^{\circ} \mathrm{C}\right)$ and cold $\left(28^{\circ}, 25^{\circ}\right.$, and $\left.18^{\circ} \mathrm{C}\right)$ stimuli presented in separate blocks in each session. Test temperatures were chosen on the basis of previous studies of LTN on the arm (Green \& Schoen, 2005; Green \& Zaharchuk, 2001) and of pilot tests in which they were found adequate to produce LTN on the hand in at least some individuals. Testing was conducted using a within-subjects design in which all subjects served in every condition. Subjects were assigned to one of eight groups that were created to counterbalance the order in which body site (hand vs. forearm), stimulus condition (static vs. dynamic), and stimulus temperature (warm vs. cold) were tested across subjects.

Testing on the hand. At the beginning of each session, the experimenter adjusted the diameter of the handgrip thermode to accommodate the size of the subject's right hand. Following this adjustment, the subject submerged the hand in a $35^{\circ} \mathrm{C}$ water bath for $2-5 \mathrm{~min}$ to raise skin temperature to the desired base temperature of $33^{\circ} \mathrm{C}\left( \pm 0.5^{\circ}\right)$. A disposable nitrile examination glove was worn on the hand to keep it dry, and a 36-ga thermocouple was slipped inside the glove to measure skin temperature at the base of the fingers. When baseline temperature was reached, the subject withdrew the hand from the bath, removed the glove, and grasped the thermode. Thereafter, the skin in contact with the Peltier modules was held at $33^{\circ} \mathrm{C}$ while the rest of the hand (like the rest of the arm surrounding the module array) was uncontrolled. Care was taken that the position of the hand allowed the Peltier modules to contact the fleshy pads of the distal and middle phalanxes and the metacarpophalangeal joints on the palm at the base of each finger. A mirror was placed behind the thermode to help subjects adjust their fingers as necessary and to allow the experimenter to monitor finger placement throughout testing. Thermodes that contacted the thumb, thenar, and hypothenar eminences were not stimulated and remained at base temperature throughout the experiment.

In the static condition, the hand remained in contact with the thermode throughout each block of testing. Subjects were instructed to grip the thermode with just enough force to keep the hand in contact with the modules. The experimenter said, "Ready, attend now," to signal the beginning of a trial before she triggered the thermal stimulus. Thus, in the static condition, warming and cooling occurred while the skin was in continuous contact with the modules. Only one of the four fingers and its associated metacarpophalangeal pad were stimulated on each trial (a total of three Peltier modules). At the end of the 5-sec stimulus, the subjects rated sensation intensity and quality using the left hand to control the computer mouse. The testing sequence was repeated after a 60 -sec ITI, with stimuli delivered to a different finger and metacarpophalangeal pad. When the static condition came first in a session, it was followed by a 3-min break before the dynamic condition was tested. During the break, subjects rested the right hand and wore a cotton mitten to help keep its temperature stable.

In the dynamic condition, subjects began with the hand grasping the thermode as in the static condition, but, at the beginning of each trial, they were instructed to release their grip and to relax the hand, such that their fingers and palm were a few millimeters above the surface of the modules. The thermal stimulus was then triggered. When the target temperature was reached, the instruction was given to grasp the thermode as before. Thus, in the dynamic condition, the skin contacted the modules after they had been heated or cooled to the target temperature. The PID loop of the thermal control system maintained the skinthermode surface temperature at the target temperature during skin contact. Contact lasted $5 \mathrm{sec}$, after which subjects were instructed to release the thermode and to make their ratings of thermal and nociceptive sensations. Once the ratings were completed, the subjects grasped the thermode again to return skin temperature to $33^{\circ} \mathrm{C}$ during a 60 -sec ITI. To reduce thermal adaptation due to repeated stimulation, the fingers and metacarpophalangeal pads were stimulated sequentially, so that stimulation at each site was not repeated again for $4 \mathrm{~min}$. To further protect against stimulus-induced adaptation, temperatures were presented as an ascending intensity series (i.e., $38^{\circ}, 40^{\circ}$, and $43^{\circ} \mathrm{C}$ for heating and $28^{\circ}, 25^{\circ}$, and $18^{\circ} \mathrm{C}$ for cooling). Each testing session included a total of 24 trials in which the three cool temperatures and three warm temperatures were presented once each to the four fingers and metacarpophalangeal pads.

Testing on the forearm. The conditions of thermal stimulation for the forearm paralleled those for the hand. In the static condition, the thermode remained in place against the arm throughout each block of testing, such that heating and cooling occurred in the presence of static contact with the thermode array. To produce the same total area of thermal stimulation on the arm as on the hand, stimuli were delivered through three Peltier modules (from one of the four rows of the thermode array) for $5 \mathrm{sec}$. As with stimulation of the four fingers, the four rows were stimulated sequentially across trials, so that the time between stimulation at each site was $4 \mathrm{~min}$.

In the dynamic condition, a trial began with the experimenter lifting the thermode from the arm before triggering the thermal stimulus. Once the target temperature was reached, the thermode was brought back down against the skin for $5 \mathrm{sec}$, then lifted off again, and the subject was instructed to make his or her ratings. After the ratings were made and the temperature of the thermode had returned to $33^{\circ} \mathrm{C}$, the thermode was returned to the arm for the 60 -sec ITI. As with the hand, each testing session contained 24 trials.

\section{Data Analysis}

Because intensity ratings obtained on the gLMS for groups of subjects tended to follow a log-normal distribution, after averaging the ratings obtained across the four digits (on the hand) and the four 
rows of the module array (on the arm) for a given contact condition and temperature, the means were converted to logarithms. Zeros were first removed from the data by replacing them with the lowest nonzero rating that is physically possible to make on the computerbased gLMS program (0.24), which corresponds to one pixel above no sensation. This practice made the smallest intensity rating possible equal to the $\log _{10}$ of 0.24 , or -0.62 . ANOVAs were calculated using a repeated measures design in the general linear model module of Statistic (version 7.1; Statsoft, Tulsa, OK). Tukey HSD tests were used to evaluate specific post hoc contrasts.

\section{RESULTS}

\section{Hand Versus Forearm}

Heating and cooling were both rated as more intense on the forearm than they were on the hand. Separate ANOVAs (with test site, temperature, and sensation quality as factors) conducted for static cooling and heating both revealed main effects of test site [cooling, $F(1,43)=31.6, p<.0001$; heating, $F(1,43)=14.8, p<$ $.0001]$. However, the converging functions for the hand and forearm, visible in Figures 2A and 2C, indicate that, for cooling, the difference in perceived intensity between sites was temperature-dependent [stimulation site $\times$ temperature interaction, $F(2,86)=14.5, p<.0001]$. At $18^{\circ} \mathrm{C}$, the difference between the hand and the forearm was no longer significant for either thermal or nociceptive sensations (Tukey HSD, $p$ s $>.05$ ). In contrast, the functions produced by heating remained parallel across temperatures. For those data, a significant interaction was instead found between stimulation site and sensation quality $[F(1,43)=45.0, p<.0001]$, which confirmed that, for heating, differences in intensity ratings between the hand and the forearm were larger for nociceptive sensations than for thermal sensations (Figures 2B and 2D). The average difference in $\log _{10}$ ratings of warmth and heat on the two sites was just 0.13 , or $35 \%$, whereas the average difference in nociceptive ratings was 0.53 , or $339 \%$. Thus, nociceptive sensations induced by heating were more than three times stronger on the forearm than on the hand at comparable thermode temperatures, with nociceptive sensations on the hand rising above barely detectable only at $43^{\circ} \mathrm{C}$.

Independent of test site, log-mean nociceptive ratings during static contact were much lower during cooling than during heating. At $18^{\circ} \mathrm{C}$, nociceptive ratings were between barely detectable and weak on both sites, whereas, at $43^{\circ} \mathrm{C}$, nociceptive ratings were above weak on the hand and approached strong on the forearm. The source of the lower mean ratings for cold can be seen in Figure 3 , which contains scatterplots of the intensity ratings for thermal and nociceptive sensations on the forearm versus the hand at $25^{\circ}$ and $40^{\circ} \mathrm{C}$. All four Pearson $r$ correlations were statistically significant $(p<.05)$, indicating that subjects tended to be similarly sensitive (or insensitive) to stimuli on both test sites. Most notably, 15 subjects reported no nociceptive sensations at either site when the stimulus was $25^{\circ} \mathrm{C}$ (Figure 3C). In contrast, only 3 subjects reported no nociceptive sensations at either site when the stimulus was $40^{\circ} \mathrm{C}$ (Figure 3D).

\section{Static Versus Dynamic Contact}

Figure 4 compares ratings of thermal sensations (e.g., cold or warmth) under conditions of static versus dynamic contact on the hand and forearm. Looking first at the results for cooling (Figures 4A and 4C), dynamic contact tended to produce lower cold ratings overall. An ANOVA comparing cold intensity ratings on the hand and forearm confirmed that there was a main effect of contact condition $[F(1,43)=50.1, p<.0001]$ and a three-way interaction among the effects of test site, contact condition, and temperature $[F(2,86)=5.9, p<.005]$. The latter interaction was driven by a tendency for the difference between contact conditions to decrease at colder temperatures. Convergence of the intensity functions was more pronounced on the hand, where the difference between contact conditions disappeared at $18^{\circ} \mathrm{C}$ (Tukey HSD, $p>.05)$. The results were similar for heating, except that the differences between contact conditions were smaller. Although there was a significant main effect of contact condition $[F(1,43)=9.7, p<.005]$, the effect was qualified by a significant condition $\times$ temperature interaction $[F(2,86)=10.2, p<.001]$. Post hoc tests indicated that, at both sites, the effect of contact condition was significant only at $38^{\circ} \mathrm{C}$ (Tukey HSD, $p<.05$ ). The three-way interaction among site, condition, and temperature fell just short of significance $[F(2,86)=2.9, p=.059]$.

As in previous studies, the results indicated that, for both sites and for both heating and cooling, contact suppression was greater for nociceptive sensations than for thermal sensations. To provide an accurate assessment of the amount of nociceptive suppression required that subjects be omitted from the analysis if they reported little or no burning, stinging, or pricking in the static contact condition. Thus, subjects were only included in the analysis if they reported greater than barely detectable burning, stinging, or pricking at $25^{\circ}$ or $40^{\circ} \mathrm{C}$ on the site of interest. Figure 5 contains the $\log _{10}$-mean nociceptive ratings from 21 subjects for cooling and from 23 subjects on the hand and 36 subjects on the arm for heating. Dynamic contact reduced ratings of nociceptive sensations at $18^{\circ}$ and $25^{\circ} \mathrm{C}$ by approximately $50 \%$ and $75 \%$, respectively, on both the hand and the forearm. It was not possible to analyze the difference in amount of suppression on the hand and arm directly, because not all of the same subjects reported criterion-level nociceptive sensations on both sites (see Figure 2). However, repeated measures ANOVAs conducted on the data from each site confirmed there were main effects of condition in every case. The results of the ANOVAs differed across sites only with respect to the presence or absence of three-way interactions among the effects of condition, temperature, and sensation quality. For cooling, negligible nociceptive sensations on the hand at $28^{\circ} \mathrm{C}$ caused this interaction to be significant $[F(2,4)=$ $11.7, p<.0005$ ], whereas, for warming, a sharp reduction in suppression at $43^{\circ} \mathrm{C}$ led to a three-way interaction on the forearm $[F(2,70)=6.1, p<.005]$. For the purpose of simplicity, the thermal sensation data for these subjects are not shown, since the pattern of results was the same as for all subjects combined (Figure 4). 
Hand vs. Forearm

A

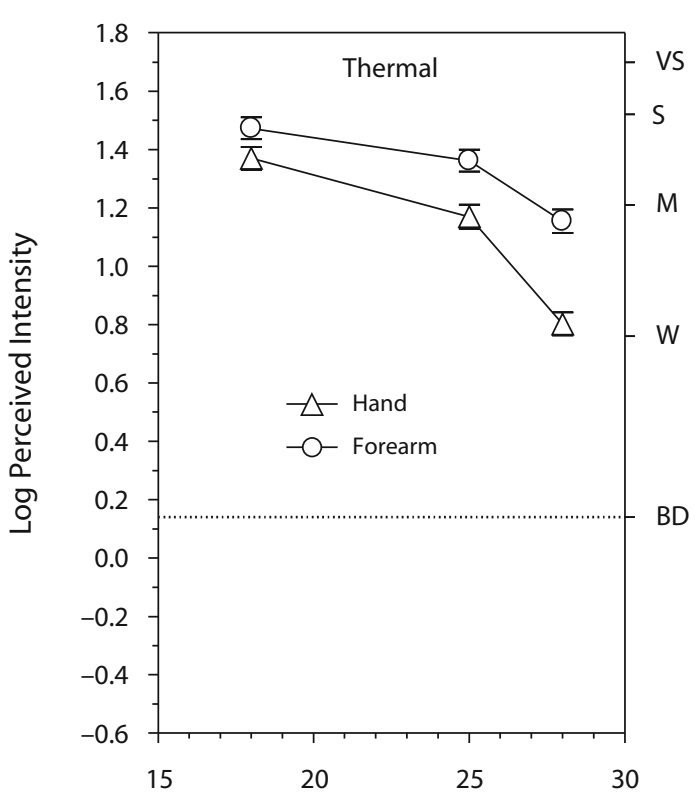

C

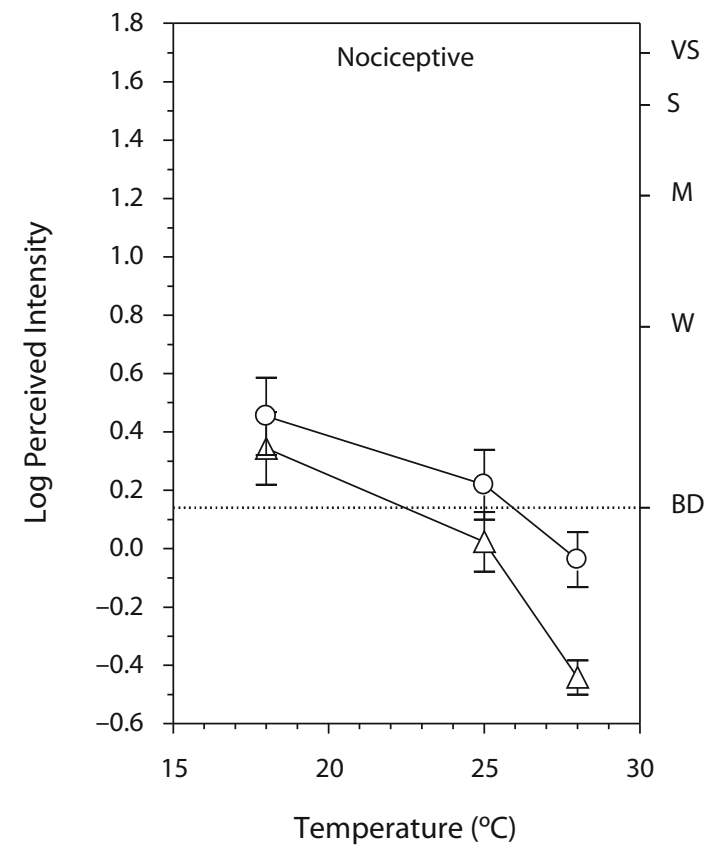

B

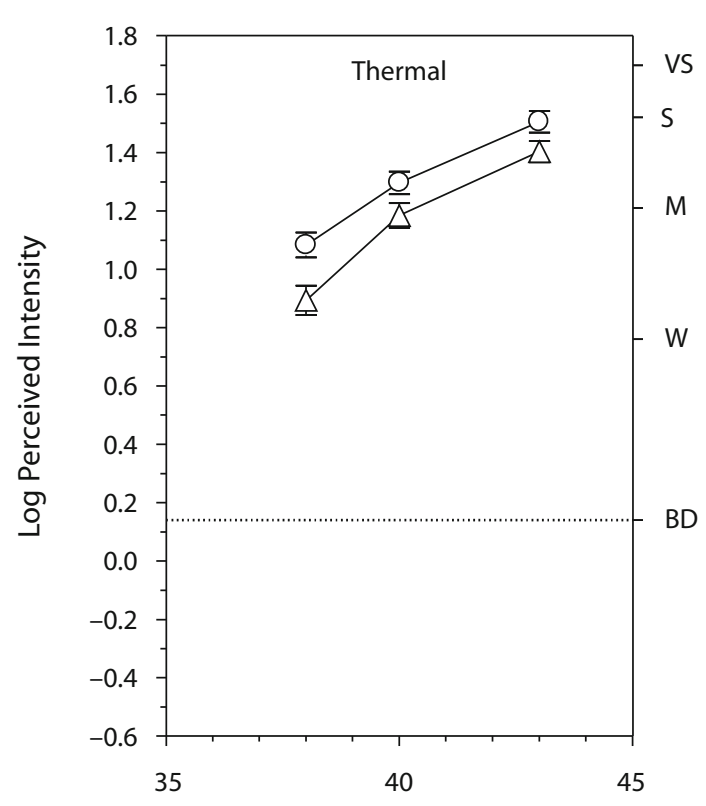

D

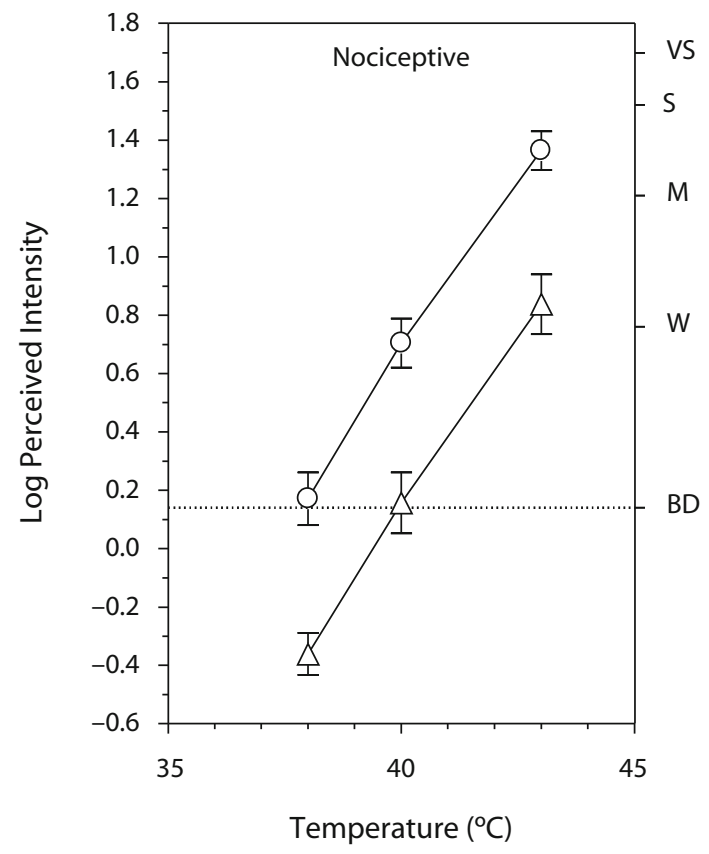

Figure 2. Log-mean intensity ratings are shown for thermal $(A, B)$ and nociceptive $(C, D)$ sensations reported on the hand (triangles) versus the forearm (circles) as a function of thermode temperature. All data are from the static contact condition. Letters on the right $y$-axis represent verbal descriptors on the rating scale: BD, barely detectable (highlighted with a dotted line); W, weak; M, moderate; S, strong; VS, very strong. Vertical bars represent standard errors of the means. 
A

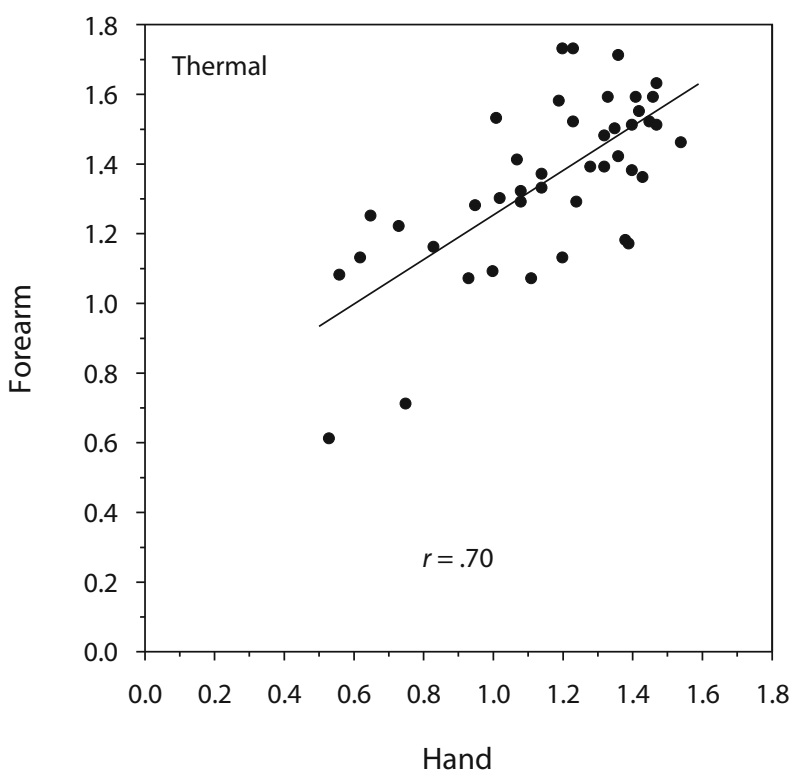

C

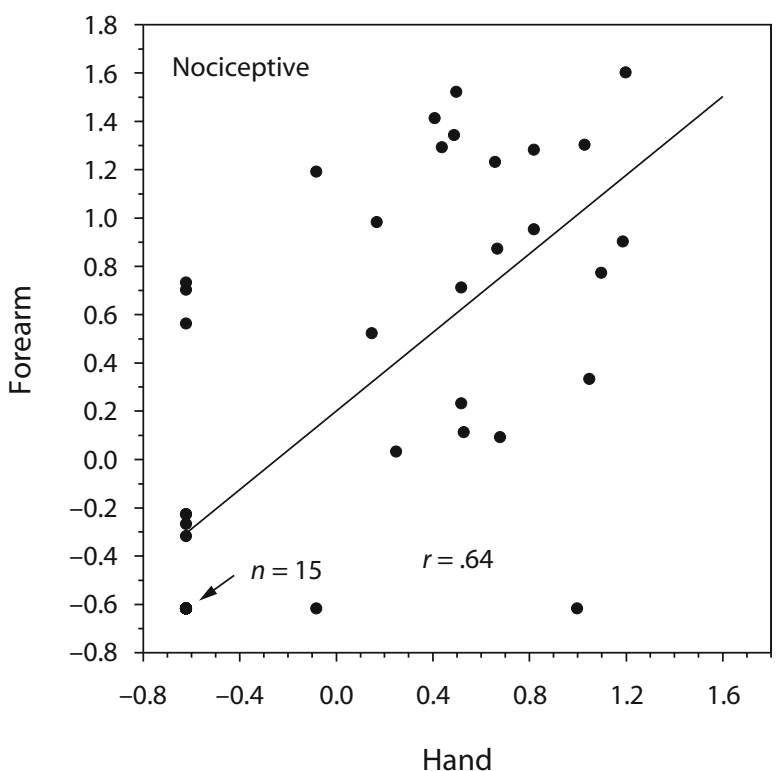

B $\quad 40^{\circ} \mathrm{C}$

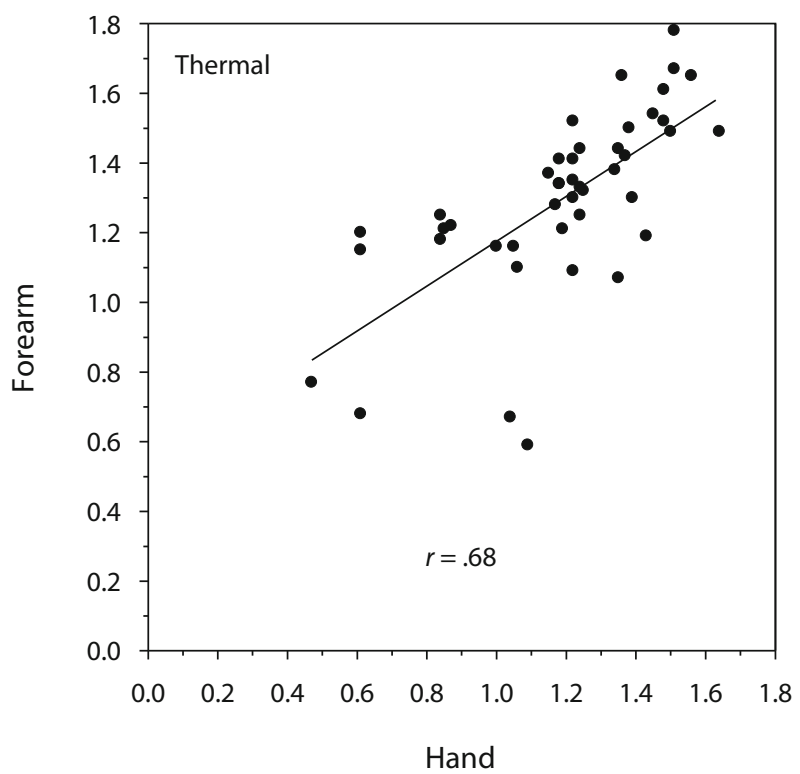

D

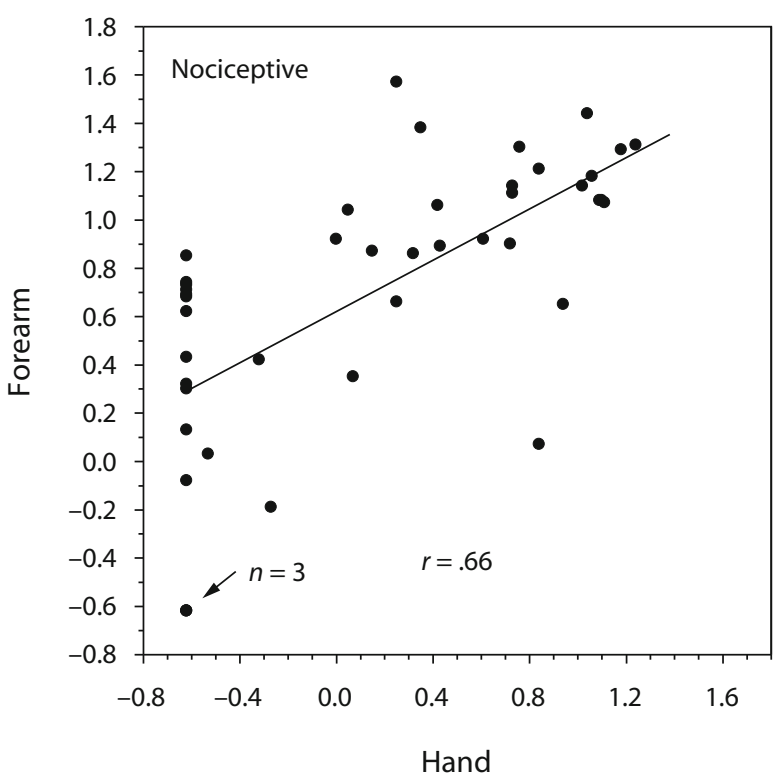

Figure 3. Scatterplots that compare log-mean ratings of thermal (A, B) and nociceptive (C, D) sensations given by individual subjects to the $25^{\circ}$ and $40^{\circ} \mathrm{C}$ stimuli presented to the hand versus the forearm. Least-squares best fit lines are shown for each data set, together with Pearson $r$ correlation coefficients. In $C$ and $D, n=15$ and $n=3$ refer to the number of subjects who reported no nociceptive sensations on either the forearm or the hand in response to the $25^{\circ}$ and $40^{\circ}$ stimuli, respectively. 
Static vs. Dynamic Contact: Thermal

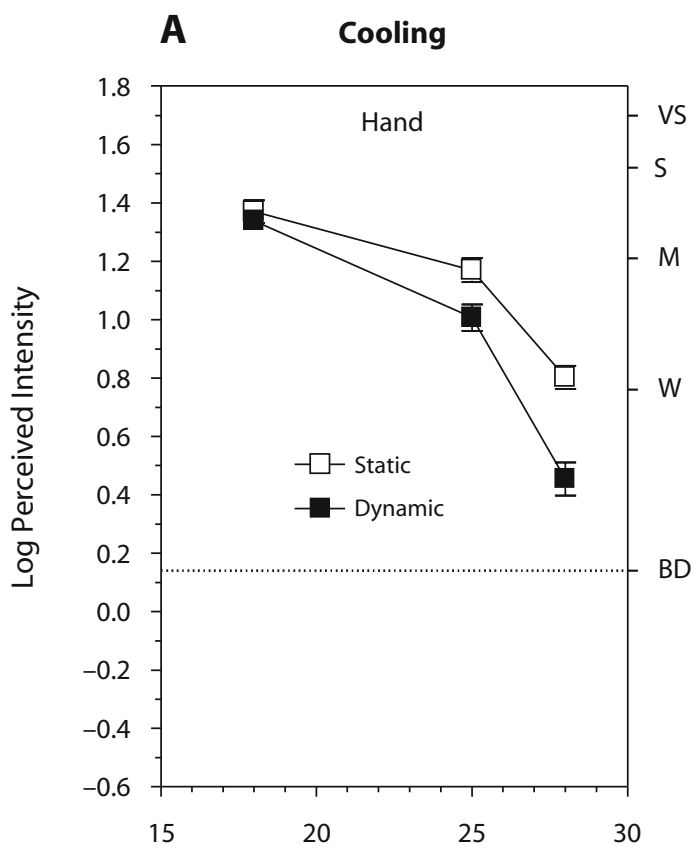

C

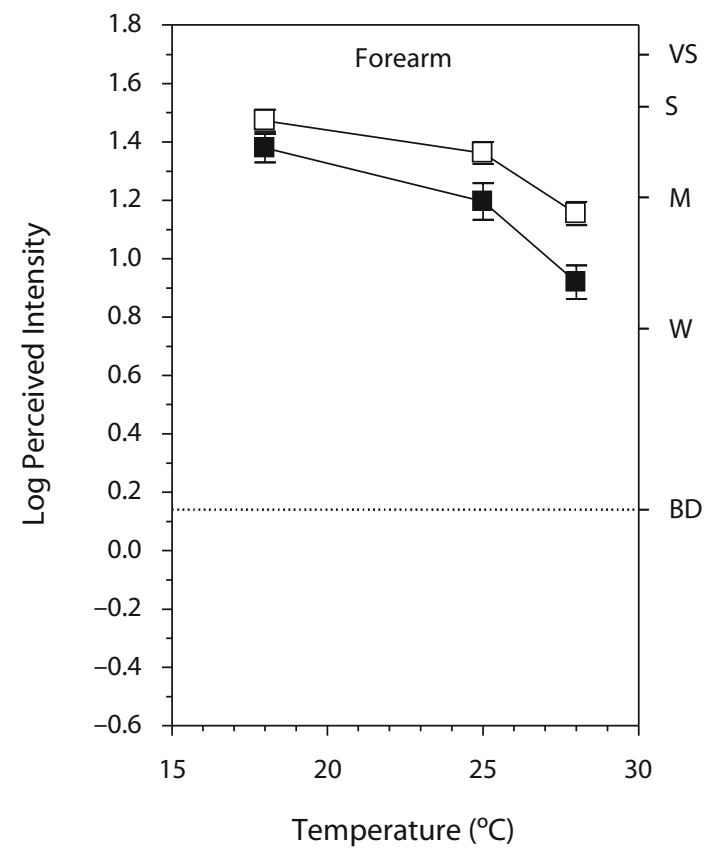

B Heating

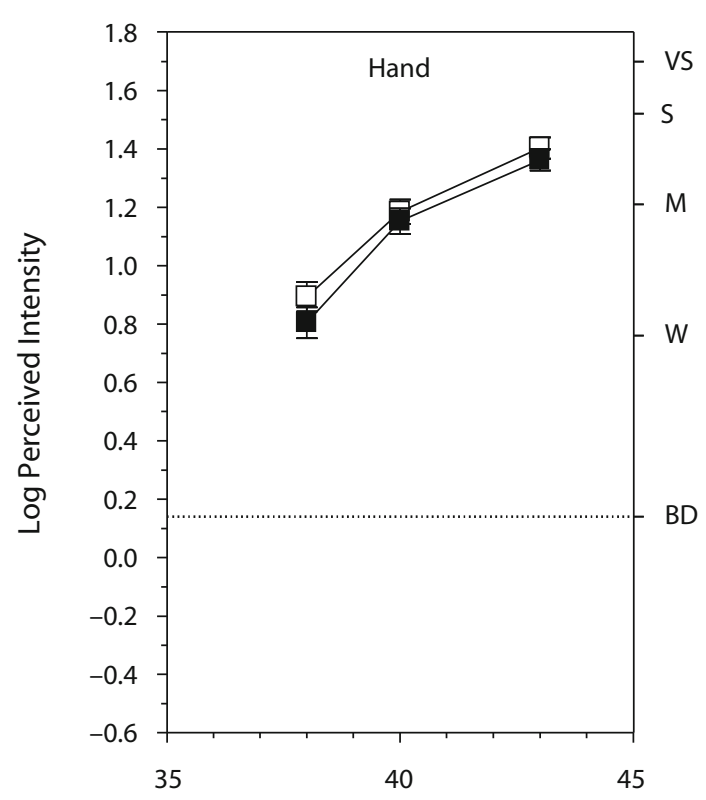

D

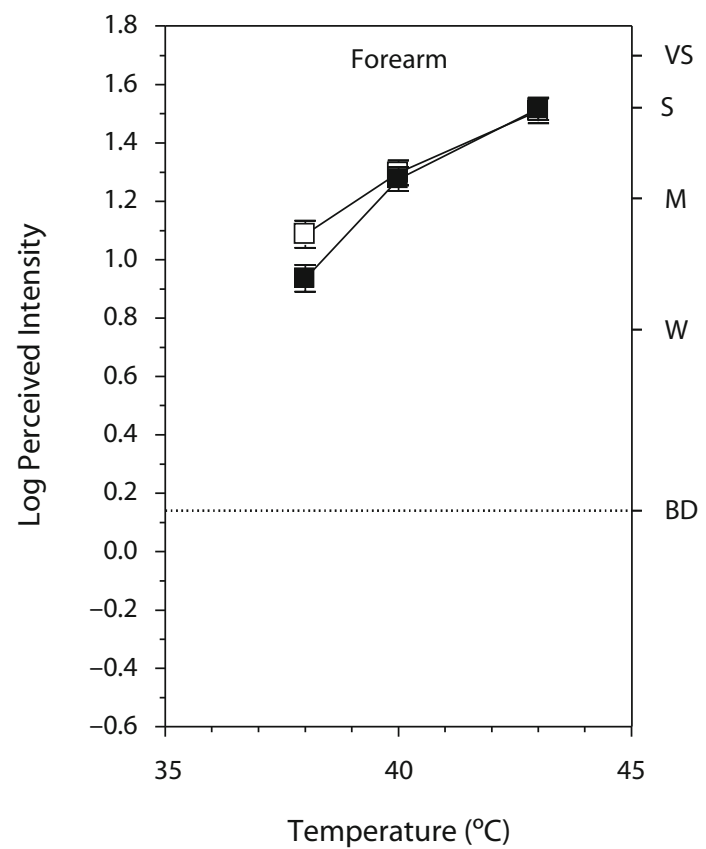

Figure 4. Log-mean intensity of thermal sensations for the hand $(A, B)$ and forearm $(C, D)$ in the static (open squares) versus dynamic (filled squares) contact conditions as a function of thermode temperature. Letters on the right $y$-axis represent verbal descriptors on the rating scale: $\mathrm{BD}$, barely detectable (highlighted with a dotted line); W, weak; M, moderate; S, strong; VS, very strong. Vertical bars represent standard errors of the means. 
Static vs. Dynamic Contact: Nociception

A

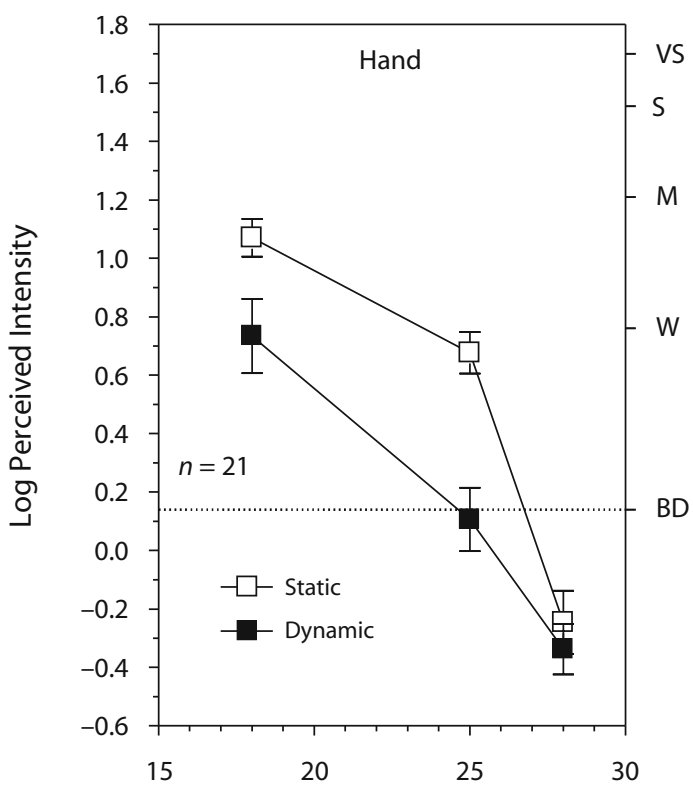

C

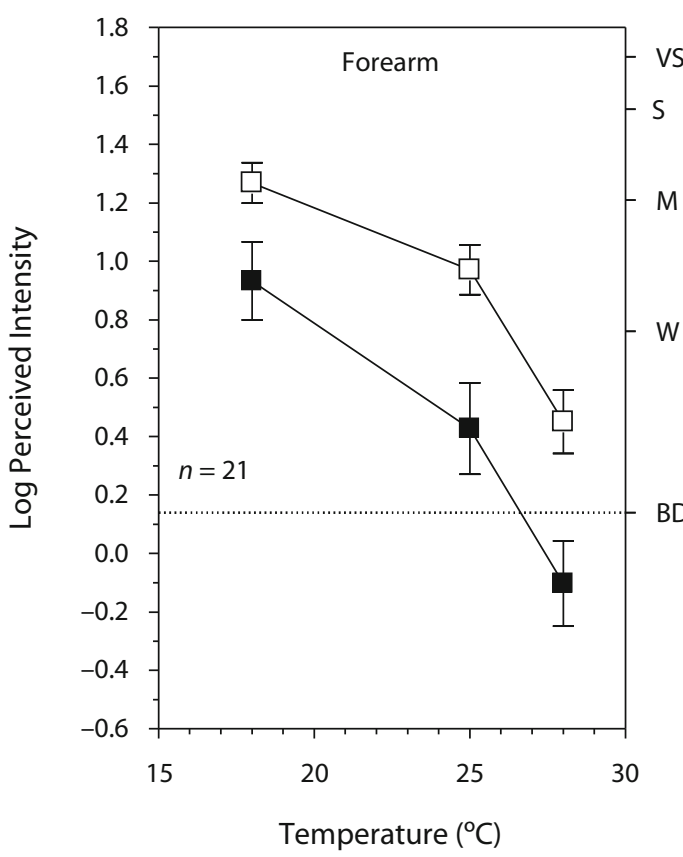

B

Heating

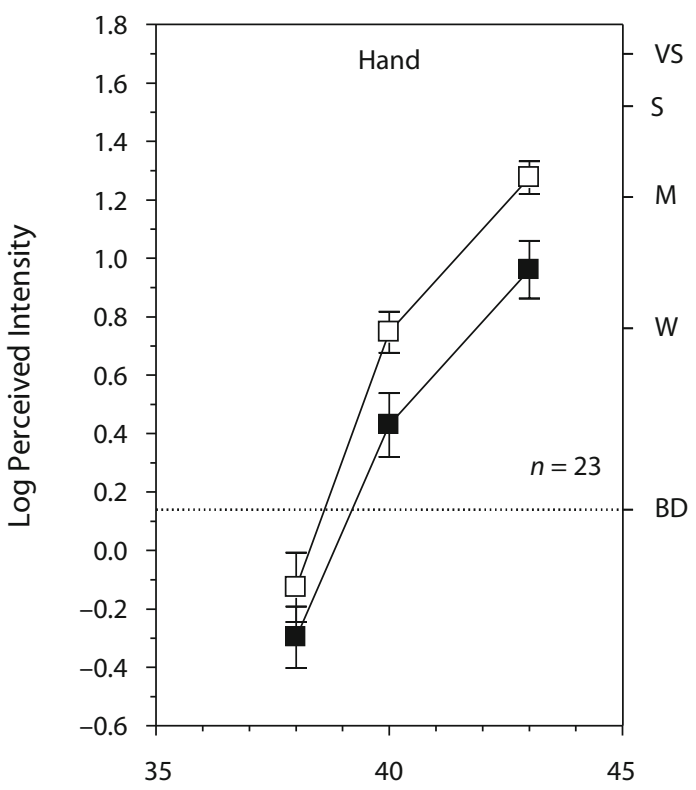

D

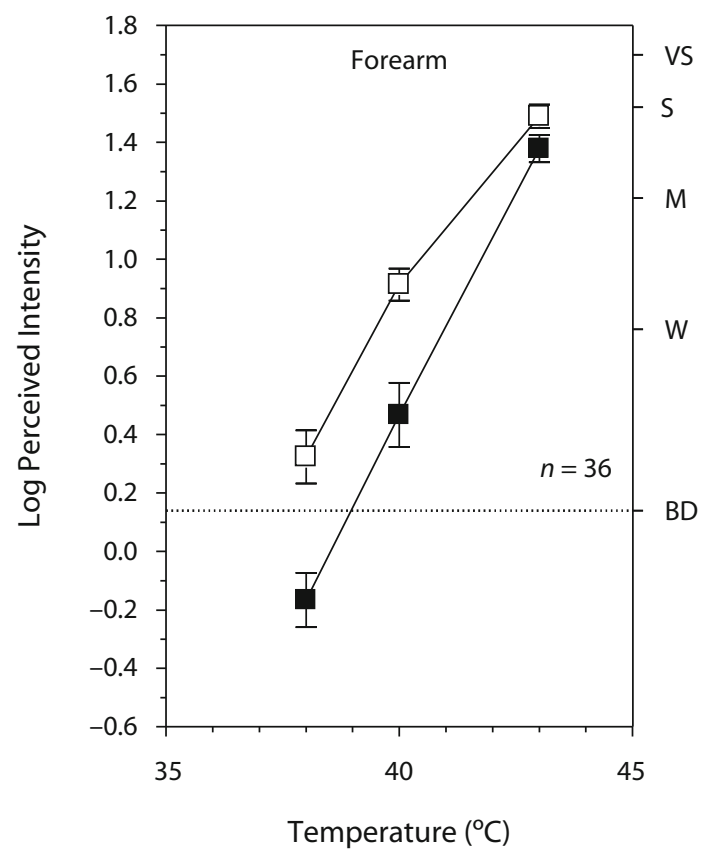

Figure 5. Log-mean intensity of nociceptive sensations for the hand $(A, B)$ and forearm $(C, D)$ in the static (open squares) versus dynamic (filled squares) contact conditions as a function of thermode temperature. Data are from subjects who reported greater than barely detectable burning, stinging, or pricking at $25^{\circ} \mathrm{C}$ (for cooling) or $40^{\circ} \mathrm{C}$ (for warming) on the site of interest. Letters on the right $y$-axis represent verbal descriptors on the rating scale: $\mathrm{BD}$, barely detectable (highlighted with dotted line); W, weak; M, moderate; S, strong; VS, very strong. Vertical bars represent standard errors of the means. 


\section{Sensation Quality}

Figure 6 displays the sensation qualities evoked by static stimulation of the hand and forearm during heating and cooling. To provide an accurate picture of the sensations experienced by individuals who reliably reported LTN, the data were obtained from the subset of subjects whose data are shown in Figure 5. The pattern of results was the same for the dynamic condition (not shown), except that the frequencies of nociceptive ratings were lower. Of most interest in Figure 6 is the evidence that what differed most between the forearm and the hand was the overall frequency of reports, rather than the relative frequencies with which different qualities were reported. Stinging/pricking was the most frequently reported nociceptive sensation on both the hand and the forearm during cooling, whereas burning was the most frequently reported nociceptive sensation on both sites during heating. Consistent with the greater sensitivity of the forearm, the $43^{\circ} \mathrm{C}$ stimulus produced a much higher incidence of pain on the forearm than on the hand $(50.6 \%$ and $14.8 \%$, respectively).

\section{DISCUSSION}

The present results show that nociceptive sensations can be perceived during static contact cooling and warming of the hand to innocuous temperatures, and that dynamic contact significantly suppresses these sensations. Dynamic contact also tends to reduce the intensity of thermal sensations (i.e., warm, cool, cold, hot), but to a lesser degree. Because haptic perception involves dynamic contact, these findings indicate that the perceived temperature of objects and surfaces normally depends on sensory interactions between thermal and tactile stimulation.
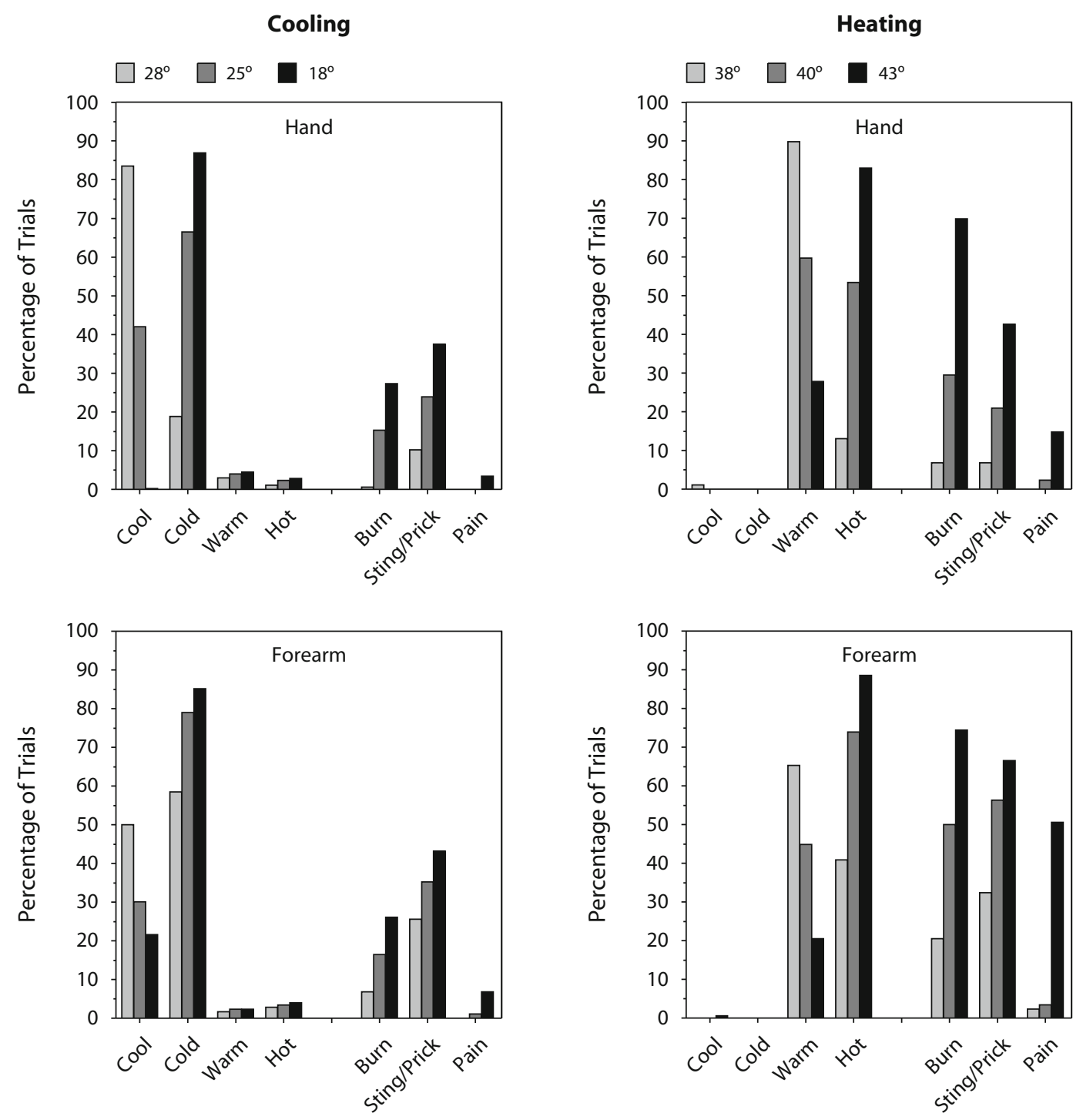

Figure 6. Shown are the percentage of trials on which specific sensation qualities were reported on the hand (top) and forearm (bottom) for the three cooling temperatures $\left(28^{\circ}, 25^{\circ}, 18^{\circ} \mathrm{C}\right)$ and three heating temperatures $\left(3^{\circ}, 4^{\circ}, 4^{\circ} \mathrm{C}\right)$ that were tested. Data from all subjects were included. 
Evidence of nociceptive sensations on the glabrous skin of the hand, as well as on the hairy skin of the forearm, demonstrates that LTN is a general property of cutaneous thermal sensitivity. However, nociceptive sensations were reported less often and were rated as less intense on the hand than on the forearm. In the static contact condition, the two mildest temperatures $\left(28^{\circ}\right.$ and $\left.37^{\circ} \mathrm{C}\right)$ evoked significant nociceptive sensations on the forearm but not on the hand. Because the average heat threshold for polymodal nociceptors is near $40^{\circ} \mathrm{C}$ (Bessou \& Perl, 1969; Price \& Dubner, 1977; Tillman et al., 1995) and because stimulation at $43^{\circ} \mathrm{C}$ was rated as painful on $14.8 \%$ of trials, it is possible that, on the hand, heating causes burning, stinging, or pricking sensations only when temperature-sensitive nociceptors are stimulated. A similar argument could be made with respect to cooling the hand to $25^{\circ} \mathrm{C}$, a temperature that is near the thresholds of the most sensitive cold-sensitive nociceptors (Georgopoulos, 1976; LaMotte \& Thalhammer, 1982). Although this possibility cannot be ruled out, differences in skin thickness between the hand and the arm must also be considered. Because the stratum corneum of palmar skin contains several more cell layers than does the stratum corneum of forearm skin (Ya-Xian, Suetake, \& Tagami, 1999), a given thermode temperature should cool or heat thermoreceptors and nociceptors less on the palm than on the forearm. Support for this possibility comes from studies showing that heat pain thresholds are significantly higher on the hand than on the forearm (Taylor, McGillis, \& Greenspan, 1993) and that higher temperatures are required on the palm to produce cold pain and heat pain equivalent to that produced on the back of the hand (Harrison \& Davis, 1999; Iannetti, Zambreanu, \& Tracey, 2006). In addition, after comparing heat pain ratings and evoked potential latencies produced by contact versus laser heating, Iannetti et al. concluded that the absence of first pain on palmar skin was due to its thicker stratum corneum rather than to a lack of A-delta mechanoheat nociceptors, as had previously been proposed (Treede, Meyer, Raja, \& Campbell, 1995). Finally, the similarity in nociceptive qualities that were reported on the hand and forearm is consistent with stimulation of the same classes of primary afferent fibers at both body sites.

The neural basis of LTN remains unclear. It is very likely, however, that at least some thermally-sensitive afferent fibers that express the cold and menthol-sensitive channel TRPM8 (Colburn et al., 2007; Dhaka et al., 2007; Peier et al., 2002) relay stimulation to the nociceptive system. First, there is abundant psychophysical evidence that menthol induces burning and stinging sensations as well as cold sensations (Cliff \& Green, 1994; Green, 1992; Green \& Schoen, 2007; Wasner, Schattschneider, Binder, \& Baron, 2004). Second, neurophysiological evidence has shown that TRPM8 is coexpressed on some rat dorsal root ganglion neurons with the heat-sensitive nociceptive channel TRPV1 (Okazawa et al., 2004), and neurons in the rat trigeminal subnucleus caudalis that are stimulated by fibers sensitive to menthol are also stimulated by fibers that are sensitive to chemical irritants (Zanotto, Merrill, Carstens, \& Carstens, 2007). Third, recent studies have shown that knockout mice deficient in TRPM8 show large deficits in response to cold under conditions that normally produce cold allodynia
(Colburn et al., 2007; Dhaka et al., 2007). Similarly, the heat-sensitive channels TRPV3 and TRPV4, which have thresholds well below $40^{\circ} \mathrm{C}$, and are thus candidate warm receptors (Chung, Lee, \& Caterina, 2003; Chung, Lee, Mizuno, Suzuki, \& Caterina, 2004; Smith et al., 2002; Xu et al., 2002), have been implicated in the sensitivity to heat pain and heat hyperalgesia, respectively (Moqrich et al., 2005; Todaka, Taniguchi, Satoh, Mizuno, \& Suzuki, 2004). It is interesting to speculate whether variation in the genetic expression of these receptors may be a significant contributor to individual differences in perception of LTN.

At present, it is only possible to speculate about the mechanism by which dynamic contact inhibits LTN. Previous evidence that touch and vibration can inhibit painful sensations has most often been explained in terms of the Gate Control Theory (Craig \& Rollman, 1999; Doehring, 1989; Handwerker, Iggo, \& Zimmermann, 1975; Melzack \& Wall, 1965), which postulates that an inhibitory circuit in the spinal cord causes afferent activity conducted in small, mostly unmyelinated fibers that have high thresholds (e.g., $\mathrm{CPNs}$ ) to be blocked by activity conducted in large, myelinated afferent fibers that have low thresholds (e.g., tactile and cold fibers). Although it remains a plausible theory in principle, the neurophysiology of the gate-control mechanism remains very much in question, and descending inhibitory processes, which are also known to be involved in tactile analgesia, may also play a role (Handwerker et al., 1975; Sandkühler, 1996; Wall, 1978). Moreover, the idea that touch in general inhibits pain fails to account for the fact that contact suppression is limited to dynamic tactile stimulation. Recent data also imply that the spatiotemporal properties of the tactile stimulus are important for contact suppression. Specifically, suppression did not occur in significant amounts when a thermode was lightly drawn across the lubricated surface of the skin instead of being touched to its surface (Green et al., 2008). Both forms of stimulation produced weak but clearly perceptible tactile sensations, yet normal (vertical) contact led to suppression, whereas lateral mechanical stimulation did not. This difference, which was observed using a thermal stimulator as small as $1 \mathrm{~mm}$ in diameter, strongly implied that contact suppression resulted primarily from stimulation of low-threshold mechanoreceptors that are more sensitive to vertical impact than to skin deformation produced during lateral movement.

The evidence that dynamic contact inhibits cold more strongly than warmth does on both the hand and forearm implies that tactile stimulation interacts preferentially with central processing of cold stimulation. The source of this preferential interaction is unclear, although it is well established that cold sensitivity and mechanoreception are closely related, even at the earliest stages of sensory processing. For example, the ability of cold to stimulate some low-threshold mechanoreceptors (Burton, Terashima, \& Clark, 1972; Hahn, 1971; Hensel \& Zotterman, 1951) has been used to explain Weber's illusion, in which objects placed on the skin feel heavier when they are cold than when they are thermally neutral (Stevens \& Green, 1978). More recently, CNS neurons that respond to both tactile and cold stimulation have also been identified (Hutchison, Tsoukatos, \& Dostrovsky, 1997; Kadohisa, Rolls, \& Ver- 
hagen, 2004; Tsuboi et al., 1993). Although there is as yet no evidence that implicates these central and peripheral neural interactions with inhibitory processes, an absence of similar bimodal neurons that respond to heating and touch is consistent with the smaller effect of touch on warmth observed here.

Although the amount of contact suppression obtained on the hand and arm was comparable overall, it cannot be ruled out that some fraction of what was observed for the hand resulted from inhibition related to efference copy or corollary discharge. These neurophysiological phenomena derive from active movement of the fingers and limbs and have been shown to inhibit tactile stimulation from the skin (Chapman \& Beauchamp, 2006; Milne, Aniss, Kay, \& Gandevia, 1988; Nelson, 1996). Consistent with this possibility are the results of a previous study in which subjects rated a surface as less cold when they actively felt it compared with when the surface was moved passively across the finger (VanDoorn, Richardson, Wuillemin, \& Symmons, 2005). However, the difference in cold ratings was small, and the conditions of the experiment were quite different from those of the present one. In addition, efference discharge associated with joint and muscle activity has been shown to inhibit mechanically evoked stimulation (Chapman \& Beauchamp, 2006; Milne et al., 1988; Nelson, 1996), which would be expected to reduce rather than enhance contact suppression. Thus, although the present results cannot rule out a contribution to contact suppression by a mechanism that is unique to active touch, any such effect is likely to be relatively small.

Thus, the present results add to the evidence first provided by thermal referral (Green, 1977, 1978, 1979) that touch contributes in fundamental ways to normal temperature perception. The possibility that touch refers thermal sensations to external objects was first suggested by Ernst Weber in 1846 (Ross \& Murray, 1978). Weber observed that, in the absence of touch, the surface of the skin was perceived as warm or hot whether it was heated by blood from within or by a radiant source from without. Only "if [a] hot object ... is actually pressed against the skin, [is there] no doubt that the heat comes externally to us and we feel that the object ... is itself hot" (p. 144). Stated more generally, tactile stimulation may serve to bind thermal sensations to the surfaces and objects that produce them. LTN and contact suppression appear to serve a different function. Green and Schoen (2005) have speculated that these phenomena provide an adaptive solution to the sometimes conflicting demands placed on thermoreception by thermoregulation and haptic perception. Because heat exchange via radiation and convection is much less efficient than heat exchange via contact with conductive surfaces, thermoregulation and haptic perception often require different levels of sensitivity. During whole-body exposures in cold environments, the loss of significant amounts of body heat are often accompanied by only small changes in skin temperature (Adair, 1977). LTN may provide an aversive, nociceptive signal of heat loss under such conditions that is inhibited when a similar amount of skin cooling results from contact with conductive materials in moderate environments (e.g., $25^{\circ}-28^{\circ} \mathrm{C}$ ). The same argu- ment can be applied to heat-induced LTN: An intense radiant source (e.g., fire) that rapidly heats the skin by a few degrees should be avoided, whereas contact with a warm surface (e.g., $36^{\circ}-38^{\circ} \mathrm{C}$ ) that causes a comparable rise in skin temperature should not be perceived as threatening. Whether or not this hypothesis turns out to be correct, the present results make it clear that haptic thermal perception cannot be understood solely in terms of the properties of the thermal stimulus.

\section{AUTHOR NOTE}

The author thanks Carol Akirav for collecting the data reported here and for performing preliminary statistical and graphical analyses. This research was supported in part by National Institutes of Health Grant RO1 NS38463. Correspondence concerning this article should be addressed to B. G. Green, John B. Pierce Laboratory, Yale University School of Medicine, 290 Congress Avenue, New Haven, CT 06519 (e-mail: green@jbpierce.org).

\section{REFERENCES}

AdAIR, E. R. (1977). Skin, preoptic, and core temperatures influence behavioral thermoregulation. Journal of Applied Physiology, 42, 559564.

Bartoshuk, L. M., Duffy, V. B., Fast, K., Green, B. G., Prutkin, J., \& SNYDER, D. J. (2003). Labeled scales (e.g., category, Likert, VAS) and invalid across-group comparisons: What we have learned from genetic variation in taste. Food Quality \& Preference, 14, 125-138.

Bessou, P., \& PerL, E. R. (1969). Response of cutaneous sensory units with unmyelinated fibers to noxious stimuli. Journal of Neurophysiology, 32, 1025-1043.

Bini, G., Cruccu, G., Hagbarth, K.-E., Shady, W., \& Torebjörk, E. (1984). Analgesic effect of vibration and cooling on pain induced by intraneural electrical stimulation. Pain, 18, 239-248.

Burton, H., Terashima, S. I., \& Clark, J. (1972). Response properties of slowly adapting mechanoreceptors to temperature stimulation in cats. Brain Research, 45, 401-416.

CAIN, W. S. (1973). Spatial discrimination of cutaneous warmth. American Journal of Psychology, 86, 169-181.

Chapman, C. E., \& Beauchamp, E. (2006). Differential controls over tactile detection in humans by motor commands and peripheral reafference. Journal of Neurophysiology, 96, 1664-1675.

Chung, M. K., Lee, H., \& Caterina, M. J. (2003). Warm temperatures activate TRPV4 in mouse 308 keratinocytes. Journal of Biological Chemistry, 278, 32037-32046.

Chung, M. K., Lee, H., Mizuno, A., Suzuki, M., \& Caterina, M. J. (2004). TRPV3 and TRPV4 mediate warmth-evoked currents in primary mouse keratinocytes. Journal of Biological Chemistry, 279, 21569-21575.

Cliff, M. A., \& Green, B. G. (1994). Sensory irritation and coolness produced by menthol: Evidence for selective desensitization of irritation. Physiology \& Behavior, 56, 1021-1029.

Colburn, R. W., Lubin, M. L., Stone, D. J., Jr., Wang, Y., LaWRENCE, D., D'ANDREA, M. R., ET AL. (2007). Attenuated cold sensitivity in TRPM8 null mice. Neuron, 54, 379-386.

Craig, J. C., \& Rollman, G. B. (1999). Somesthesis. Annual Review of Psychology, 50, 305-331.

Dhaka, A., Murray, A. N., Mathur, J., Earley, T. J., Petrus, M. J., \& Patapoutian, A. (2007). TRPM8 is required for cold sensation in mice. Neuron, 54, 371-378.

Dimmick, F. L. (1915). On the localization of pure warm sensations. American Journal of Psychology, 26, 142-150.

Doehring, K. M. (1989). Relieving pain through touch. Advancing Clinical Care, 4, 32-33.

GEORGOPOULOS, A. P. (1976). Functional properties of primary afferent units probably related to pain mechanisms in primate glabrous skin. Journal of Neurophysiology, 39, 71-83.

Green, B. G. (1977). Localization of thermal sensation: An illusion and synthetic heat. Perception \& Psychophysics, 22, 331-337.

GREEN, B. G. (1978). Referred thermal sensations: Warmth versus cold. Sensory Processes, 2, 220-230. 
GreEn, B. G. (1979). Thermo-tactile interactions: Effects of touch on thermal localization. In D. R. Kenshalo (Ed.), Sensory functions of the skin of humans (pp. 223-240). New York: Plenum.

GreEN, B. G. (1992). The sensory effects of l-menthol on human skin. Somatosensory \& Motor Research, 9, 235-244

GREEN, B. G., \& AKIRAV, C. (2007). Individual differences in temperature perception: Evidence of common processing of sensation intensity of warmth and cold. Somatosensory \& Motor Research, 24, 71-84.

Green, B. G., \& Pope, J. V. (2003). Innocuous cooling can produce nociceptive sensations that are inhibited during dynamic mechanical contact. Experimental Brain Research, 148, 290-299.

Green, B. G., Roman, C., Schoen, K., \& Collins, H. (2008). Nociceptive sensations evoked from 'spots' in the skin by mild cooling and heating. Pain, 135, 196-208.

Green, B. G., \& Schoen, K. L. (2005). Evidence that tactile stimulation inhibits nociceptive sensations produced by innocuous contact cooling. Behavioral Brain Research, 162, 90-98.

Green, B. G., \& Schoen, K. L. (2007). Thermal and nociceptive sensations from menthol and their suppression by dynamic contact. Behavioral Brain Research, 176, 284-291.

Green, B. G., Shaffer, G. S., \& Gilmore, M. M. (1993). Derivation and evaluation of a semantic scale of oral sensation magnitude with apparent ratio properties. Chemical Senses, 18, 683-702.

GREEN, B. G., \& ZAHARCHUK, R. (2001). Spatial variation in sensitivity as a factor in measurements of spatial summation of warmth and cold. Somatosensory \& Motor Research, 18, 181-190.

HAHN, J. F. (1971). Thermal-mechanical stimulus interactions in lowthreshold C-fiber mechanoreceptors of cat. Experimental Neurology, 33, 607-617.

Handwerker, H. O., IgGo, A., \& Zimmermann, M. (1975). Segmental and supraspinal actions on dorsal horn neurons responding to noxious and non-noxious skin stimuli. Pain, 1, 147-165.

Harrison, J. L., \& Davis, K. D. (1999). Cold-evoked pain varies with skin type and cooling rate: A psychophysical study in humans. Pain, 83, 123-135.

Hensel, H., \& ZotTerman, Y. (1951). The response of mechanoreceptors to thermal stimulation. Journal of Physiology, 115, 16-24.

Hutchison, W. D., Tsoukatos, J., \& Dostrovsky, J. O. (1997). Quantitative analysis of orofacial thermoreceptive neurons in the superficial medullary dorsal horn of the rat. Journal of Neurophysiology, 77, 3252-3266

Iannetti, G. D., Zambreanu, L., \& Tracey, I. (2006). Similar nociceptive afferents mediate psychophysical and electrophysiological responses to heat stimulation of glabrous and hairy skin in humans. Journal of Physiology, 577, 235-248.

InUi, K., Tsusi, T., \& KaKIGI, R. (2006). Temporal analysis of cortical mechanisms for pain relief by tactile stimuli in humans. Cerebral Cortex, 16, 355-365.

Jones, F. N., Singer, D., \& Twelker, P. A. (1962). Interactions among the somesthetic senses in judgments of subjective magnitude. Journal of Experimental Psychology, 64, 105-109.

Kadohisa, M., Rolls, E. T., \& Verhagen, J. V. (2004). Orbitofrontal cortex: Neuronal representation of oral temperature and capsaicin in addition to taste and texture. Neuroscience, 127, 207-221.

LaMotte, R. H., \& Thalhammer, J. G. (1982). Response properties of high-threshold cutaneous cold receptors in the primate. Brain Research, 244, 279-287.

Longe, S. E., Wise, R., Bantick, S., Lloyd, D., Johansen-Berg, H., McGlone, F., \& Tracey, I. (2001). Counter-stimulatory effects on pain perception and processing are significantly altered by attention: An fMRI study. NeuroReport, 12, 2021-2025.

Melzack, R., \& Wall, P. D. (1965). Pain mechanisms: A new theory. Science, 150, 971-979.

Milne, R. J., Aniss, A. M., Kay, N. E., \& Gandevia, S. C. (1988). Reduction in perceived intensity of cutaneous stimuli during movement: A quantitative study. Experimental Brain Research, 70, 569-576.

Moqrich, A., Hwang, S. W., Earley, T. J., Petrus, M. J., Murray, A. N., SPENCER, K. S., ET AL. (2005). Impaired thermosensation in mice lacking TRPV3, a heat and camphor sensor in the skin. Science, 307, 1468-1472.

NeLSON, R. J. (1996). Interactions between motor commands and somatic perception in sensorimotor cortex. Current Opinion in Neurobiology, 6, 801-810.
Okazawa, M., Inoue, W., Hori, A., Hosokawa, H., Matsumura, K., \& Kobayashi, S. (2004). Noxious heat receptors present in coldsensory cells in rats. Neuroscience Letters, 359, 33-36.

Peier, A. M., Moqrich, A., Hergarden, A. C., Reeve, A. J., AndersSON, D. A., Story, G. M., ET AL. (2002). A TRP channel that senses cold stimuli and menthol. Cell, 108, 705-715.

Pertovaara, A. (1979). Modification of human pain threshold by specific tactile receptors. Acta Physiologica Scandinavica, 107, 339-341.

Price, D. D., \& Dubner, R. (1977). Neurons that subserve the sensorydiscriminative aspects of pain. Pain, 3, 307-338.

Ross, H. E., \& Murray, D. J. (1978). E. H. Weber: The sense of touch. New York: Academic Press.

SANDKÜHLER, J. (1996). The organization and function of endogenous antinociceptive systems. Progress in Neurobiology, 50, 49-81.

Simone, D. A., \& KaJander, K. C. (1996). Excitation of rat cutaneous nociceptors by noxious cold. Neuroscience Letters, 213, 53-56.

Simone, D. A., \& Kajander, K. C. (1997). Responses of cutaneous A-fiber nociceptors to noxious cold. Journal of Neurophysiology, 77, 2049-2060

Smith, G. D., Gunthorpe, M. J., Kelsell, R. E., Hayes, P. D., REILLY, P., FACER, P., ET AL. (2002). TRPV3 is a temperature-sensitive vanilloid receptor-like protein. Nature, 418, 186-190.

Stevens, J. C., \& Green, B. G. (1978). Temperature-touch interaction: Weber's phenomenon revisited. Sensory Processes, 2, 206-219.

Taus, R. H., Stevens, J. C., \& Marks, L. E. (1975). Spatial localization of warmth. Perception \& Psychophysics, 17, 194-196.

TaYlor, D. J., McGillis, S. L., \& Greenspan, J. D. (1993). Body site variation of heat pain sensitivity. Somatosensory \& Motor Research, 10, 455-465.

Tillman, D. B., Treede, R. D., Meyer, R. A., \& Campbell, J. N. (1995). Response of C fibre nociceptors in the anaesthetized monkey to heat stimuli: Correlation with pain threshold in humans. Journal of Physiology, 485, 767-774.

Todaka, H., Taniguchi, J., Satoh, J., Mizuno, A., \& Suzuki, M. (2004). Warm temperature-sensitive transient receptor potential vanilloid 4 (TRPV4) plays an essential role in thermal hyperalgesia. Journal of Biological Chemistry, 279, 35133-35138.

Treede, R. D., Meyer, R. A., Raja, S. N., \& Campbell, J. N. (1995). Evidence for two different heat transduction mechanisms in nociceptive primary afferents innervating monkey skin. Journal of Physiology, 483, 747-758.

Tsuboi, Y., Iwata, K., Muramatsu, H., Yagi, J., Inomata, Y., \& SuMINO, R. (1993). Response properties of primary somatosensory cortical neurons responsive to cold stimulation of the facial skin and oral mucous membrane. Brain Research, 613, 193-202.

VanDoorn, G. H., Richardson, B. L., Wuillemin, D. B., \& SymMONS, M. A. (2005). Modification of magnitude estimations in thermotactile perception during self-generated and externally generated movements. Perception, 34, 231-235.

WALL, P. D. (1978). The gate control theory of pain mechanisms. A reexamination and re-statement. Brain, 101, 1-18.

Wall, P. D., \& Cronly-Dillon, J. R. (1960). Pain, itch, and vibration. Archives of Neurology, 2, 365-375.

Wasner, G., Schattschneider, J., Binder, A., \& Baron, R. (2004). Topical menthol - a human model for cold pain by activation and sensitization of C nociceptors. Brain, 127, 1159-1171.

Xu, H., Ramsey, I. S., Kotecha, S. A., Moran, M. M., Chong, J. A., Lawson, D., ET AL. (2002). TRPV3 is a calcium-permeable temperature-sensitive cation channel. Nature, 418, 181-186.

YARNITSKy, D., KUnIN, M., BRIK, R., \& SPRECHER, E. (1997). Vibration reduces thermal pain in adjacent dermatomes. Pain, 69, 75-77.

Ya-Xian, Z., Suetake, T., \& Tagami, H. (1999). Number of cell layers of the stratum corneum in normal skin: Relationship to the anatomical location on the body, age, sex and physical parameters. Archives of Dermatological Research, 291, 555-559.

Zanotto, K. L., Merrill, A. W., Carstens, M. I., \& Carstens, E. (2007). Neurons in superficial trigeminal subnucleus caudalis responsive to oral cooling, menthol, and other irritant stimuli. Journal of Neurophysiology, 97, 966-978.

(Manuscript received February 4, 2009 revision accepted for publication February 16, 2009.) 